\title{
A AUTONOMIA DECISÓRIA E O DIREITO À AUTODETERMINAÇÃO CORPORAL EM DECISÕES PESSOAIS: UMA NECESSÁRIA DISCUSSÃO
}

\author{
THE DECISIONAL AUTONOMY AND THE RIGHT TO CORPORAL SELF-DETERMINATION \\ IN PERSONAL DECISIONS: A NECESSARY DISCUSSION
}

\section{Riva Sobrado de Freitas}

Professora do Programa de Pós-Graduação em Direito da Universidade do Oeste de Santa Catarina (Unoesc). Professora assistente-doutora aposentada da Universidade Estadual Paulista Júlio de Mesquita Filho (Unesp). Pósdoutora em Direito pela Universidade de Coimbra. Doutora e mestre em Direito pela PUC/SP.

E-mail: rivafreit@gmail.com.

\section{Orides Mezzaroba}

Pós-doutor pela Universidade de Coimbra e Doutor em Direito pela Universidade Federal de Santa Catarina (UFSC). Professor nos Programas de Graduação e Pós-graduação Mestrado e Doutorado em Direito da UFSC. Coordenador do Programa de Mestrado Profissional em Direito da UFSC. Professor Colaborador do Programa de Pós-graduação em Direito da Universidade do Oeste de Santa Catarina (UNOESC). Pesquisador de Produtividade do CNPq.

E-mail: oridesmezza@gmail.com.

\section{Daniela Zilio}

Mestre em Direitos Fundamentais pela Universidade do Oeste de Santa Catarina (Unoesc). Especialista em Direito Civil e Direito Processual Civil pela Universidade do Oeste de Santa Catarina (Unoesc) e especialista no Novo Sistema Processual Civil Brasileiro pela Universidade do Oeste de Santa Catarina (Unoesc). Graduada em Direito pela Universidade do Oeste de Santa Catarina (Unoesc). Professora. Advogada.

E-mail: danielazilio@yahoo.com.br.

Recebido em: 24/08/2019

Aprovado em: 16/03/2020

RESUMO: O presente artigo tem como problema o questionamento sobre a existência da autonomia decisória e a ponderação dela como necessário alicerce para a efetivação da autodeterminação do indivíduo sobre o seu corpo. Para solver-se o questionamento, foi realizada uma pesquisa bibliográfica exploratório-explicativa, qualitativa, utilizando-se o método dedutivo. A conclusão obtida é a de que é clara a existência de um direito de exercer a autonomia decisória, que confere empoderamento às decisões particulares, e que, portanto, guarnece o ser humano em sua identidade e dignidade pessoal. Como resultado da pesquisa, dessa forma, tem-se que, é prerrogativa inerente ao ser humano o reconhecimento à sua autocompreensão, e a autonomia decisória estabelecida é imprescindível na construção desse direito.

Palavras-chave: Autonomia decisória. Autodeterminação corporal. Direito ao próprio corpo.

ABSTRACT: The present paper has as problem the questioning of the existence of decisional autonomy and its consideration as a necessary foundation for the realization of one's selfdetermination over their own body. In order to solve the questioning, it has been made a qualitative, exploratory-explanatory bibliographical research, by using the deductive method. The conclusion 
obtained is the one which is clear in reference to the existence of a right of exercising the decisional autonomy, that provides empowerment to the private decisions, and that, therefore, guards the human being in their identity and personal dignity. As a result of the research, therefore, one has that, the inherent prerogative of the human being is the recognition of their self-understanding, and the established decisional autonomy is essential in the construction of this right.

Keywords: Decisional autonomy. Corporal self-determination. Right to the own body.

SUMÁRIO: Introdução; 1 A autonomia decisória e o direito à privacidade; 2 "O meu corpo sou eu": o direito ao próprio corpo; 3 A autodeterminação corporal como essência da autonomia decisória: algumas questões; Conclusão; Referências.

\section{INTRODUÇÃO}

O corpo é o meio de comunicação de todo e qualquer indivíduo para com o mundo externo e, é através dele que são mediadas todas as relações às quais esse mesmo indivíduo participa. $\mathrm{O}$ corpo do ser humano expressa o seu modo de ser, traduz as suas intenções, e faz com que exista, de fato, convívio entre os seres. Participa, ainda, da identidade da pessoa, na medida em que o modo pelo qual ela se vê, e se coloca perante o mundo, passa pelo seu reconhecimento e sua autocompreensão corporal.

A autonomia enquanto liberdade existencial, também é um meio que possibilita ao indivíduo reconhecer-se como tal, na medida em que por meio dela ele (indivíduo) pode optar por quais caminhos pretende encaminhar a sua existência. Questiona-se, assim, a respeito da autonomia decisória mediando a relação do sujeito para com o mundo, através de seu corpo, com aquilo que neste estudo se denomina de "autodeterminação corporal".

O problema que será investigado calca-se, então, no seguinte questionamento: no que consiste a autonomia decisória enquanto substrato para a autodeterminação corporal?

Objetiva-se, logo, averiguar o que é a autonomia decisória, notadamente enquanto embasamento para a configuração do direito de autodeterminação corporal. Especificamente, temse por objetivo analisar a autonomia decisória, após, ponderar acerca do que se trata o direito ao próprio corpo, e, então, estudar a autonomia decisória enquanto norte para a autodeterminação corporal.

Para isso, a estrutura do artigo se dará da seguinte forma: primeiramente será realizada uma pontual análise acerca da autonomia decisória enquanto pilar do direito à privacidade, após, partir-se-á para a necessária explanação sobre o direito ao próprio corpo, para que, finalmente, seja possível vislumbrar, em um terceiro momento, a autodeterminação corporal como parte essencial da autonomia decisória, averiguando-se algumas importantes e dificultosas questões relacionadas ao assunto.

Justifica-se a escolha do tema pela proeminência da controvérsia jurídica relacionada a ele, já que a defesa da autonomia decisória, especialmente em relação à autodeterminação corporal, carrega consigo, justamente pelos casos nada fáceis enfrentados, certa polêmica, e bastante resistência por parte de boa parte dos pensadores e operadores do direito, e é aí que reside a importância de ponderar-se sobre, de refletir-se e de trazer à tona a discussão. Ademais, é indubitável a atualidade do tema, em tempos em que a defesa da integridade corporal mostra-se tão em evidência.

Outrossim, o tema tem uma relevância indiscutível precisamente pelo relatado, e na medida em que embasa a análise de diversas discussões que têm como nascedouro o núcleo que emana da autonomia decisória e que carregam consigo, muitas vezes, estigmas sociais, éticos e morais, para além de jurídicos, conforme será visto no tempo oportuno. 
Metodologicamente, a pesquisa calca-se em procedimentos técnicos, racionais e sistemáticos, que trazem embasamento científico, e que proporcionam alicerces lógicos à investigação. Ainda, trata-se de pesquisa de coleta bibliográfica exploratório-explicativa, qualitativa, onde se utiliza o método dedutivo, e se intenta explorar e descrever o tema em apreço, a despeito de não ter-se o intuito de esgotar a temática.

\section{A AUTONOMIA DECISÓRIA E O DIREITO À PRIVACIDADE}

Quando o assunto é autonomia, quase sempre emergem discussões teóricas relacionadas à autonomia privada e suas consequências no mundo jurídico. Pensa-se que não poderia ser diferente, até mesmo pela importância que o tema tem. A ênfase negocial do conceito e sua visualização enquanto poder de autorregulamentação de condutas, de fato, toma um lugar de destaque e é imperioso que assim seja, mesmo porque, não há dúvidas acerca da sua relevante dimensão na formalização dos negócios jurídicos.

Aliás, como bem pondera Steinmetz (2004), a autonomia privada trata-se, certamente, de um valor constitucional. Deve, portanto, ser observado e respeitado, inclusive sob o prisma contratual a ela relacionado.

Sobre isso, de certo que o seu papel no direito privado é relevantíssimo, sendo ela, inclusive, um princípio fundamental, sobretudo em relação ao direito civil, conforme o mesmo autor.

Não obstante, a perspectiva existencial ligada à autonomia, ousa-se dizer, parece trazer ainda mais contrapontos. Isso porque, quando se fala em escolhas a serem tomadas em um campo próprio de decidibilidade, a despeito do questionamento ou da aceitação do todo, nítidas são as polêmicas emanadas.

Quando se pensa na perspectiva existencial da autonomia, pensa-se, claro, na autonomia privada enquanto viés pessoal de atuação. Há, todavia, que ser explicitado aqui, que quando da menção do termo autonomia decisória, neste estudo, pensa-se ela enquanto ramo do direito à privacidade. A averiguação se dará, porquanto, sob o manto da doutrina da privacidade, advinda do direito norte-americano ${ }^{1}$.

Sobre a autonomia na perspectiva existencial do tema, ainda que não nos mesmos moldes aqui trazidos, mas de forma muito pontual, expõem Barroso e Martel (2010) que, é direito de cada pessoa a escolha dos projetos de vida, sem que ela sofra qualquer tipo de preconceito, segregação ou intolerância, por conta do que é ou das opções que faz.

Notadamente, a expressão "autonomia", quando somada à expressão "vontade", revela a sua importantíssima face vislumbrada por Immanuel Kant e sua "autonomia da vontade". Claro que, a expressão ganhou conotações jurídicas ao longo dos tempos, mas, também é certo que Kant, e a filosofia Kantiana em si, despontam com intensidade ao pensar-se sobre tal termo. Muito embora não seja exatamente a autonomia na perspectiva Kantiana que se busque aqui aprofundar (assim como não é a autonomia privada, em seu prisma negocial), não se pode deixar de fazer menção às brilhantes contribuições do autor, para que seja possível entender a autonomia da forma como hoje ela pode ser entendida.

Do mesmo modo, necessário relacionar-se que, a autonomia na perspectiva existencial foi galgada a um dos quatro princípios da bioética, portanto, o seu respeito torna-se imprescindível quando em pauta assuntos relacionados ao tema, e, da mesma forma, ao biodireito. Em que pese toda a controvérsia, é preciso que se diga que, conforme Beauchamp e Childress (2013), o princípio do respeito à autonomia, pressupõe uma forma negativa de análise, que pode ser exemplificada no

\footnotetext{
${ }^{1}$ Apesar de o artigo trabalhar com a doutrina do "right to privacy", a partir, primordialmente, dos ensinamentos de Jean L. Cohen, certamente será feito menção a institutos indispensáveis para o perfeito delinear do ensaio, como a categoria de estudo emanada do princípio da dignidade da pessoa humana, presente na Constituição Federal de 1988.
}

Revista de Direito Brasileira | Florianópolis, SC | v. 24 | n. 9 | p.168-182 | Set./Dez. 2019 
sentido de que as ações humanas não devem estar sujeitas a pressões controladoras de outras pessoas. Segundo os autores, o direito de autodeterminação, alicerce de vários direitos de autonomia, inclusive os de confidencialidade e privacidade, é correlato a essa obrigação. Sendo assim, o princípio precisa de especificação em casos concretos para que se torne um guia para as devidas condutas, de modo que, a pertinente especificação contemplará as exceções válidas.

Pois bem. Dito isto, faz-se necessário refletir a autonomia sob o viés do direito à privacidade, redimensionado, conforme alhures comentado. Assim, a autonomia sob a perspectiva da privacidade diz respeito à possibilidade de que as pessoas possam fazer escolhas e delas serem responsáveis, com base em seu caminho de vida, sem que para isso precisem expressar justificativas e sem que haja influência externa nessas decisões. A construção da identidade do ser transita pelos meandros nem sempre fáceis da autonomia decisória, e, certamente, a proteção da dignidade pessoal de cada indivíduo tem como pressuposto o respeito àquele direito.

Veja-se, senão, o que anota Jean L. Cohen (2012, p. 184-185), ao explicitar o assunto da privacidade: "os direitos de privacidade pessoal [...] não determinam os tipos de razões que alguém dá para decisões morais ou éticas ou os processos reflexivos que informam a decisão.”. Ainda, aduz Cohen (2012, p. 190-191) que: "[...] não se pode ser obrigado a revelar os motivos pessoais para essas escolhas éticas ou a aceitar, como próprias, as razões ou julgamentos do grupo.”. A autora trabalha, segundo expõe, apartada de teorias liberais ou comunitaristas, vislumbrando estritamente a privacidade que conduz à dignidade pessoal, independentemente de tais olhares.

No mesmo sentido, Cohen (2012, p. 193) traz a ideia do empoderamento do indivíduo em relação à sua identidade no sentido de que:

Nessa concepção normativa de privacidade, o que é crucial e empoderador é claramente o sentimento de controle sobre as necessidades da própria identidade, sobre o acesso a si próprio, sobre quais aspectos de si serão apresentados em que momento e a quem, juntamente com a capacidade de exigir ou renunciar às demandas por acesso. Com efeito, ela é a condição sine qua non para que alguém se entenda como uma pessoa independente - um indivíduo que merece respeito e capaz de estabelecer consideração. Em nossa sociedade, a nova doutrina da privacidade assegura, assim, mais do que um princípio abstrato de respeito pelas pessoas como agentes de suas escolhas, mais do que sigilo e solidão: conferindo autonomia decisória sobre certas questões pessoais, os direitos de privacidade asseguram ao indivíduo o reconhecimento legal de sua "competência ética" com respeito a suas autodefinições e suas decisões sobre que aspectos de si próprio trazer à baila, em que momentos e com quem. Assim, os direitos à privacidade protegem e mesmo ajudam a constituir a estrutura do reconhecimento mútuo e do ritual social por meio dos quais é reconhecida a identidade de alguém e assegurada sua individualidade. (grifo da autora)

A autora explicita que, os direitos de privacidade pessoal asseguram a todos os indivíduos a autonomia decisória, nos denominados assuntos cruciais, e de cunho pessoal, sem que, como dito, sejam determinados os porquês para as escolhas morais, ou os processos reflexivos que informam a decisão. Claro que, como refere a autora, o que é tido como um assunto pessoal crucial muda no decorrer do tempo, podendo estar, certamente, entre temas de intenso debate e conflito. Para ela:

Conquanto as pessoas não inventem as tradições, padrões e normas em que são inicialmente socializadas, na medida em que se tornam individualizadas elas inventam e reinventam a unidade de suas vidas e suas identidades singulares (naturalmente, em processos interativos e comunicativos). Elas também contribuem para reinterpretar e reinventar significados, normas, tradições e narrativas. Sendo tanto constituída como constituidora, a identidade do indivíduo concreto não é apenas um conjunto de preferências entre as quais seja possível 
escolher como se escolhe uma roupa. Mas também não é simplesmente o produto de valores comunitários, de enraizamento social, de tradições compartilhadas ou de um conjunto de papéis sociais. De fato, todos esses elementos estão abertos a interpretações conflitantes por parte dos indivíduos e subgrupos no interior de uma determinada sociedade. Precisamente porque é tarefa dos indivíduos desenvolver e expressar suas autoconcepções a partir (e no interior) de uma multiplicidade de participações e afiliações, papéis e estruturas, em que estão envolvidos, precisamente porque eles demandam reconhecimento para suas personalidades concretas, sua oportunidade para autodesenvolvimento e autoapresentação experimental requer proteção. Tal proteção propicia ao indivíduo um sentido de controle sobre suas autodefinições, sobre a síntese autocriativa que apenas ele pode conformar a partir de suas várias situações e experiências, em parte através da interação comunicativa com outros.

Ainda, Cohen (2012) defende que se retome a inquietação em relação às dimensões situadas na identidade e, nessa perspectiva, argumenta que os direitos de privacidade (na visão do "right to privacy") protegem, na medida em que são necessários para isso, segundo aduz com propriedade (2012, p. 188): "tanto a ação como a identidade, tanto a autodeterminação como a autorrealização, tanto a autonomia como a autenticidade, sem prescrever um conceito específico de pessoa em qualquer dos níveis". Para a autora, o direito à privacidade pessoal que garante o acesso e a tomada de decisões e que guarnece a multiplicidade de identidades em face de um possível nivelamento que pudesse ter em mente alguma ideia de pensamento da "maioria". Para ela, em que pese voz e participação em espaços públicos democráticos ajudem a proteger a diferença, os direitos à privacidade pessoal individual são imprescindíveis, pois protegem as precondições constitutivas mínimas para que cada indivíduo possua uma identidade própria, e asseguram, principalmente, respeito às diferenças.

Justamente nesse sentido é que há o posicionamento em relação à não necessidade de contentamento da maioria com as escolhas que cada indivíduo faz, não porque não seja importante o que o todo acata, mas porque cada pessoa sabe de si, das peculiaridades que lhe são inerentes. Não se fala em nenhum momento em contrapor ou se sobrepor aos ideais de outrem, senão unicamente em "lutar" pelos próprios e determinar, a partir daí, os caminhos da existência de cada qual, na sua esfera de privacidade. Sobre isso, assevera Cohen (2012, p. 191):

[...] Em outras palavras, o direito à privacidade pessoal envolve precisamente a liberação da obrigação de justificar as próprias ações em um processo discursivo, a liberação da necessidade de ter que oferecer razões que todos conjuntamente poderiam aceitar como suas. Para dizê-lo de outra forma, a privacidade como autonomia decisória libera o indivíduo da pressão para adotar, como suas próprias, as razões que "todo mundo" aceita. Esse telos na direção do consenso vigora para o discurso moral em termos estritos e pode constituir um ideal para decisões políticas apoiadas por sanções estatais, mas não é requerido para decisões existenciais ou éticas cobertas pelos direitos à privacidade pessoal. Em outras palavras, o direito à privacidade habilita alguém a escolher com quem procurar justificar suas decisões éticas, com quem repensar comunicativamente as concepções sobre o bem e, naturalmente, a optar por não discutir certos assuntos com ninguém mais. Pois, com respeito a decisões pessoais escudadas pela capa protetora da privacidade decisória e informacional, não importa se as razões decisivas para mim poderiam também ser aceitas por alguém mais.[...] (grifo da autora)

No mesmo sentido, Warren e Brandeis (1890) determinam que a proteção da sociedade precisa advir primariamente do reconhecimento dos direitos de cada indivíduo, reconhecendo-se, pois, cada ser como, em regra, responsável por seus atos e omissões. Igualmente, amealha-se em

Revista de Direito Brasileira | Florianópolis, SC | v. 24 | n. 9 | p.168-182 | Set./Dez. 2019 
Cohen (2012) que a proteção do direito de privacidade enquanto autonomia decisória ocorre não para a construção do bem-estar do todo, senão pois ele faz parte de um elemento indiscutivelmente central na esfera de um indivíduo. As decisões de cada pessoa devem respeito a ela mesma enquanto pertencente a si própria, e é isso que a privacidade pretende corporificar.

Porém, como denota a autora (2012, p. 197):

[...] eu diria que a ideia de integridade corporal capta uma dimensão crucial de nossa identidade situada, mas não todas as suas dimensões. Somos também indivíduos situados no sentido posto em relevo pelos comunitaristas: nós desenvolvemos autodefinições com base em recursos culturalmente disponíveis em nosso ambiente vital; nos valemos de nossa localização em um conjunto específico de instituições, relações e contextos; utilizamos (frequentemente de modo criativo) discursos que pré-estruturam em parte aquilo que pode ser dito e pensado; e, em razão de tudo isso, modelamos nossa própria contribuição criativa a nossos processos autoformativos - nossa identidade. Nossa relação com o corpo, nossa corporificação [embodiment], é o substrato crucial de nossa identidade, mas não o seu todo. [...] Assim como ocorre com as outras dimensões da privacidade, necessitamos de integridade corporal tanto na interação com outros como fora dela. (grifo da autora)

Nessa linha de pensamento que se encontram as escolhas ou as decisões íntimas ou, se assim se preferir dizer, situadas dentro do que se denomina de "zona de intimidade", ou seja, as decisões de viés pessoal dizem respeito a cada pessoa e é ela quem deve decidir se e com quem compartilhar, e não o todo por ela. Justamente aí que reside o empoderamento sobre o corpo para a tomada de cada uma dessas decisões e como pressuposto necessário, o direito ao próprio corpo.

\section{2 "O MEU CORPO SOU EU": O DIREITO AO PRÓPRIO CORPO}

O direito ao corpo frequentemente permeia as discussões éticas e jurídicas que circunscrevem assuntos nem sempre fáceis de serem ponderados. Quem defende o direito ao próprio corpo defende nada menos que a si mesmo, na medida em que o corpo de cada ser não é meramente um invólucro do que ele é. O corpo de cada ser é, pois, o próprio ser, faz parte da sua essência, inclusive, como sujeito de direito. Parece claro, então, que o corpo recebe a proteção jurídica que cabe ao conceito de pessoa. O que nem sempre resta clara é a possibilidade de cada sujeito ter o empoderamento sobre o seu corpo na tomada de algumas importantes decisões, como alhures exposto.

O sentimento de empoderamento em relação ao próprio corpo acompanha o desenvolver de todo um processo que culmina na exaltação do direito de cada pessoa de ser, de fato, autônoma. É claro que, apesar de tal sentimento ser, em princípio, intrínseco ao ser humano, o deslinde deste pensamento autônomo em relação ao direito ao próprio corpo nem sempre foi (e talvez ainda não seja) visto com "bons olhos", por assim dizer.

No entanto, sobre o direito ao corpo, delimitam com propriedade Freitas e Pezzella (2013) que, ele é parte, ou inerente, a um direito à privacidade. Nesse sentido, é verdade que ele ainda se encontra carregado de certa desconfiança no que tange a algumas de suas consequências (como aquelas que serão vistas adiante, no momento oportuno), mas, de fato, a existência desse direito, em si, parece ser inconteste.

Certamente, a discussão sobre o direito ao próprio corpo perpassa a ideia dos direitos da personalidade, como reiteram Freitas e Pezzella (2013), na medida em que estes alcançam dispositivos sobre o próprio corpo e sobre a privacidade. 
Assim sendo, os direitos da personalidade, presentes no Código Civil, entre os artigos 11 e 21, são aqueles intrinsecamente ligados ao conceito de dignidade humana, exposto na Constituição Federal de 1988, em seu artigo $1^{\circ}$, inciso III, como fundamento da República Federativa do Brasil. São destinados, ademais, a proteger o ser humano enquanto pessoa, em suas características e prerrogativas. Certamente, o elenco que figura em tal diploma legal não é taxativo, mas meramente exemplificativo, mesmo porque, a abrangência da proteção à pessoa ultrapassa e muito quaisquer dos limites estabelecidos por esses artigos que estão expressamente transcritos no texto legal.

Assim, em que pese existam divergências quanto à nomenclatura utilizada, de acordo com Bittar (1989), uma vez que alguns autores utilizam-se da expressão "direitos essenciais da pessoa", alguns outros de "direitos à personalidade ou direitos essenciais", ainda, "direitos pessoais", e, ademais, "direitos personalíssimos", é certo que, de fato, a expressão mais técnica e adotada majoritariamente pela doutrina brasileira é: direitos da personalidade. A expressão se encontra, inclusive, consagrada no Código Civil Brasileiro.

Assim, embora seja relevante o aludido, é verdade que, o que de forma indubitável importa, não é exatamente a nomenclatura utilizada para traduzir tais direitos, mas sim, sem dúvidas, a sua abrangência enquanto prerrogativas destinadas a proteger o ser humano, como pessoa.

Dessa forma, esclarece Amaral (2002) que, os direitos da personalidade são os direitos subjetivos que possuem como objetivo a proteção dos bens e valores essenciais da pessoa, abrangendo as dimensões: física, moral e intelectual. Outrossim, a dimensão psíquica também se encontra sob o manto protetor dos direitos da personalidade.

Pois bem, se os direitos da personalidade abarcam a proteção do ser humano em suas dimensões física, psíquica, moral e intelectual, certamente, o direito ao próprio corpo encontra-se guarnecido, atuando sob a égide daquele que é um conceito ainda mais consagrado (justamente o conceito "direitos da personalidade"). Apesar de já ter havido referência a isso no presente estudo, é preciso que se volte à discussão, na medida em que, e porque, o direito ao próprio corpo revela exatamente o que aqui se busca exemplificar.

Sendo assim, mister referir-se, conforme Chaves (1977), Chaves (1994), e Freitas e Zilio (2016b), que as questões relativas ao corpo e ao direito sobre ele, já vêm sendo discutidas há algum tempo, embora não com a amplitude dos tempos hodiernos.

Isso porque, os assuntos que demandam a volta do olhar do sujeito para si, e a sua redescoberta enquanto pessoa, parecem ter ganhado mais espaço na atualidade, o que, por si, já se mostra um ganho significativo. Pleitear a prerrogativa de ter, na prática, um direito sobre o próprio corpo (com o perdão do pleonasmo), traduz para a realidade o que todas as pessoas, em maior ou menor grau, buscam: justamente a exteriorização de um sentimento de liberdade, que deve, todavia, ser usada com responsabilidade.

Assim, como relacionado anteriormente, o indivíduo merece ter o direito ao controle do seu corpo, sem que para isso precise justificar-se aos demais. De outro turno, mas de maneira alguma de forma incompatível, mostra-se também importante o reconhecimento das demais pessoas sobre o controle que cada indivíduo tem sobre o seu próprio corpo, já que, como relacionam Cohen (2012) e Eisenstein (1988), sem o reconhecimento pelas outras pessoas do controle autônomo de alguém sobre o próprio corpo, e, ainda, sobre sua integridade corporal, havendo, por fim, um reconhecimento da sua dignidade, a imagem que a pessoa tem de si fica prejudicada, advindo desse prejuízo a perda da autoconfiança, e da segurança necessária para interagir de forma saudável com os outros e demonstrar os sentimentos e as necessidades que tem. É o que Habermas (2010) chama de autocompreensão, e ela, certamente, passa pelo reconhecimento alheio, conforme se denota também em Honneth (1992). Aliás, Honneth (1992) claramente explicita a retirada da pessoa de seu direito de dispor do próprio corpo, como uma forma de desrespeito, uma vez que 
caso isso ocorra, há certamente um prejuízo do reconhecimento do indivíduo, em relação a si mesmo.

Dito isso, salta aos olhos a imprescindibilidade de um direito ao próprio corpo, e a partir daí, a imprescindibilidade de que se tenha autonomia decisória sobre ele, para que o indivíduo, enquanto pessoa, possa realizar determinadas decisões, que unicamente a ele interessam.

\section{A AUTODETERMINAÇÃO CORPORAL COMO ESSÊNCIA DA AUTONOMIA DECISÓRIA: ALGUMAS QUESTÕES}

A outrora relatada autonomia decisória aglutina no seu conceito a ideia de proteção a decisões eminentemente íntimas, e de conteúdo pessoal. Tanto é assim, que Wolff (1950) relata que o sentimento de autodeterminação é primordial para a percepção do que significa para alguém ser, de fato, uma pessoa, no inteiro sentido da palavra.

Portanto, a autodeterminação corporal encontra-se como que, pode-se dizer, em duas bases aparentemente distintas daquela, ou seja, como consequência do seu exercício, mas antes disso, como pressuposto para que ela própria exista. Apesar da aparente paradoxal ou dicotômica conclusão, pensa-se ser exatamente dessa forma a relação entre esses direitos. Explica-se: a autodeterminação corporal pode sim ser visualizada a partir da autonomia decisória, no sentido de ser dela uma consequência lógica, já que aquela alicerça o indivíduo na tomada de decisões íntimas e pessoais, e, perfeitamente, as decisões relacionadas ao próprio corpo se encontram dentro do conceito de intimidade abarcado pela autonomia decisória. Ocorre que, parece ser também latente a premissa de que o direito ao corpo é pressuposto para a própria efetivação da autonomia decisória, ou para sua própria existência, isso porque, é necessário que se vislumbre que, para a tomada de decisões de cunho pessoal, primeiramente, o indivíduo em questão precise, e possa, empoderar-se do próprio corpo para que então, munido da privacidade para decidir, possa refletir a sua autonomia. Decidir autonomamente questões íntimas revela antes de mais nada, e em uma realidade outrora discutível, a premente necessidade de tomar, o ser, a posse de seu corpo, nas suas diferentes dimensões e, somente então, exercer verdadeiramente a sua autonomia de decisão.

Nesta seara argumentativa, resta claro que, o direito ao próprio corpo tem especial razão de ser, até porque o exercício da autonomia pleiteada pressupõe o controle do indivíduo sobre o seu corpo, não porque se perceba o corpo como objeto negociável, mas porque, ele é concebido como elemento imprescindível para a configuração da identidade de cada ser, na medida em que o corpo do indivíduo é, a bem da verdade, o próprio indivíduo: não são coisas apartáveis, como argumenta Eisenstein (1988). Sendo assim, o direito à integridade psicofísica, verdadeiro direito da personalidade, subsidia ainda mais o direito de escolha por uma morte digna e menos dolorosa, solidificando a proteção conferida ao indivíduo em suas dimensões: física, psicológica, e moral, em face da indignidade de uma sobrevida carregada de sofrimento.

Aliás, conforme Freitas e Zilio (2016b), o direito de autodeterminação sobre o corpo é amparado pelo direito à identidade pessoal, também inerente à personalidade humana, uma vez que o reconhecimento da pessoa, em sua identidade, passa certamente pelo seu reconhecimento na dimensão corporal, como já explicitado alhures. O corpo é, pois, o veículo de comunicação de cada ser humano com o mundo que lhe é externo, e a identidade desse ser se constrói pela análise do corpo como parte intrínseca ao seu desenvolvimento.

Parece claro, então, que a autodeterminação corporal perpassa o nem um pouco fácil, embora necessário caminho da autocompreensão corporal, ponderada por Habermas (2010) e já elencada em Freitas e Zilio (2016b).

Ainda, acerca da autodeterminação, explicitam Barroso e Martel (2010) que ela abarca a prerrogativa de discernir acerca dos ideais de vida e de desenvolvimento da personalidade, obviamente, com a devida responsabilidade na tomada das decisões e intimamente, com as consequências delas advindas. Os autores explicitam a capacidade de autodeterminação descrita 
enquanto inerente ao que denominam de dignidade como autonomia. Assim, elencam os autores, também, a necessidade de que sejam conferidas as condições para o exercício da autodeterminação como aspecto determinante (condições econômicas, educacionais, psicofísicas), na medida em que é primordial, para eles, que se promovam meios adequados para que a liberdade (como denominam), seja real, e não somente retórica.

A autodeterminação corporal, de seu turno, comumente refere-se à autonomia em relação ao próprio corpo, ao direito de empoderamento sobre ele para a tomada de decisões íntimas, pessoais, e que nem sempre precisam ser externadas ao todo, embora por vezes esse todo exerça uma espécie de controle sobre as pessoas, fazendo-as crer que a coletividade prepondera ainda que em assuntos estritamente pessoais. Como se aufere em Beauchamp e Childress (2013, p. 444), "O princípio de respeito à autonomia inclui, portanto, o direito de decidir, na medida do possível, o que irá acontecer a si mesmo - ao próprio corpo, à informação sobre a própria vida, aos próprios segredos etc.”.

Nesta senda, busca-se, a partir de agora, trazer alguns desses assuntos, que ilustram perfeitamente o exposto, conforme será visto.

Sobre a autodeterminação corporal para o uso de tatuagens, relatam Freitas e Pezzella (2013) que a tatuagem é, pois, uma maneira de expressão da estética pessoal e individual, que por sua vez emana do exercício da autonomia decisória sobre o próprio corpo, ou, como aqui se preferiu denominar, da autodeterminação corporal. As autoras relatam sua preocupação em relação ao exercício da autonomia sobre o corpo no que toca às tatuagens justamente porque não podem ser estas, unicamente, por si, o motivo limitador para acesso a, por exemplo, cargos públicos².

Ademais, de certo que quando se fala em autodeterminação corporal como substrato ou base para a configuração de decisões que culminam em acontecimentos polêmicos, como é o caso da morte digna (principalmente quando externada por meio da eutanásia e do suicídio assistido), e do aborto, a questão toma proporções significativamente maiores, por, supostamente, estar-se diante de decisões vida/morte.

Assim, ainda que não seja o intuito principal do artigo esmiuçar detalhadamente cada uma dessas questões, pensa-se que, no caso do "morrer com dignidade", o exercício da autodeterminação corporal para o fim de optar pela morte ocorrida de maneira humanizada, e, quiçá, antecipada, não traduz a opção pela morte em detrimento da vida, mas a opção por viver o ato da morte, como último ato de vida, da forma e de acordo com o modo pelo qual toda essa vida foi vivida, como já exposto em Freitas e Zilio (2016b) e Freitas e Zilio (2016a).

Aliás, explicitam Freitas e Baez (2014) que, o morrer com dignidade esbarra em uma série de caminhos e, de outro modo, também são inúmeros os caminhos disponíveis para a sua efetivação, tendo em vista, dos dois modos, a avançada tecnologia na área médica na atualidade. Barroso e Martel (2010, p. 101) sustentam, defendendo a morte ocorrida em seu tempo e sem, ao menos, a penúria de uma obstinação terapêutica, que:

[...] a medicina e a tecnologia contemporâneas são capazes de transformar o processo de morrer em uma jornada mais longa e sofrida do que o necessário, em uma luta contra a natureza e o ciclo natural da vida. Nessa hora, o indivíduo deve poder exercer sua autonomia para que a morte chegue na hora certa, sem sofrimentos inúteis e degradantes. Toda pessoa tem direito a uma morte digna.

Certamente, o momento de terminalidade da vida humana não é nada fácil em nenhuma das inúmeras possíveis situações que dele podem emanar. Mas, ao menos ao que parece, impor a continuidade de uma sobrevida carregada de indignidade e sem a menor integridade psicofísica em

\footnotetext{
${ }^{2}$ Obviamente, quando as tatuagens revelam qualquer tipo de desequilíbrio que demonstre a incapacidade do candidato para o exercício do cargo público, há que ser levado isso em consideração, sem dúvidas. Todavia, claramente o que é relevante é o desequilíbrio demonstrado, e não a tatuagem em si.
}

Revista de Direito Brasileira | Florianópolis, SC | v. 24 | n. 9 | p.168-182 | Set./Dez. 2019 
detrimento de acolher a autonomia decisória do paciente que deseja ter-lhe a morte antecipada, traduz o desrespeito a uma série de direitos que são a ele inerentes, e, por outro lado, não fere, como dito, o direito de viver, mas denota a opção pela vivência do último ato de vida, que é a morte, de maneira autônoma. Aliás, é o que com extrema propriedade assevera Philippe Ariès, em sua obra "O homem diante da morte", quando explicita que "A morte deve apenas se tornar a saída discreta, mas digna, de um vivo sereno, de uma sociedade solícita que não esfacela nem perturba demais a ideia de uma passagem biológica, sem significado, sem esforço nem sofrimento e, finalmente, sem angústia" (ARIÈS, 2014, p. 827).

É verdade que, lidar com o dilema da morte é ir ao encontro de uma das "partes" mais difíceis da existência humana, e se diz isso tanto daquele em que a morte teoricamente se aproxima (paciente terminal), quanto daqueles que precisam estar junto dele. Sobre o assunto, aliás, explicita Pessini (2009) que a vida humana, do início ao fim, reveste-se de uma série de acontecimentos e de uma série de sentimentos e, de fato, o adeus a alguém que está prestes a morrer não é nada fácil.

Logicamente, essa dor deve ser vivida, contudo, nem mesmo o sofrimento dos seus pares pode justificar a obrigação de alguém, de suportar um final de vida indigno e/ou um tratamento indesejado. Menos ainda, anseios advindos de verdadeira obstinação terapêutica, ou, porque não, imposições por parte do Estado para que a sobrevida seja mantida.

É claro que, em nenhum momento prega-se a obrigação do profissional da medicina em contrariar as suas convicções pessoais para colocar em prática o desejo de outrem, até porque isso não é permitido nem pela ordem jurídica, nem pelos preceitos éticos que norteiam a profissão, e muito menos pelas normas da classe. Ainda que a hipótese fosse (ou ainda que seja) legal, o médico não tem obrigação de violar a sua consciência. Mas, na multiplicidade de ideais que existem, não são poucos os profissionais que concordam com a primazia absoluta da autonomia do paciente em casos de estágios de terminalidade e sofrimento, e a tendência é cada vez maior pelo respeito ao princípio ético da autonomia, em que pese óticas paternalistas ainda remanesçam na classe. Então, como já ocorrem em outros casos, e inclusive no caso da morte antecipada em outros países, se o médico assistente se recusa a atender a vontade do paciente, deve haver o direito a recorrer a um segundo profissional, para que o faça sem o ferimento aos seus preceitos éticos, morais, e mesmo pessoais.

Felizmente, na atualidade as relações de saúde estão migrando de uma ética paternalista, em direção à afirmação da autonomia decisória enquanto poder de autodeterminação sobre o próprio corpo no que se refere às questões relativas à vida e à saúde. Tanto é assim que a autonomia, como explicitado anteriormente, foi elevada à categoria de princípio básico no que se relaciona à ética biomédica, e, em verdade, segue-se o caminho do empoderamento do paciente sobre a sua vida e sobre a sua saúde.

Ademais, o que se busca como fim último é a proteção da autonomia decisória, da privacidade para decidir em assuntos íntimos, e o momento da morte com certeza se enquadra neste conceito, de modo que o que se deve priorizar, sob este meandro, é a sua dignificação, mediante o maior respeito possível à autodeterminação do paciente, efetivando a sua morte segundo os seus valores. Caso a vontade do paciente, expressão de sua autonomia decisória, seja a antecipação deste momento tão delicado, para abreviar o seu sofrimento, ela deve ser respeitada (em que pese jamais deva ser imposta). E o meio pelo qual se pode oferecer esse respeito à autonomia decisória do paciente que prefere antecipar a morte a vivê-la mediante um padecimento que lhe parece insustentável, e de forma contrária a seus valores, é a legalização das condutas pelas quais se pode chegar a ela, impondo os limites necessários à efetivação. É certo que o caminho para tanto será sinuoso, já que o assunto é delicado e extremamente controvertido, mas, é necessário e urgente refletir-se sobre.

Sobre o assunto, assevera Ariès (2014, p. 795): 
O médico, que durante muito tempo fora, com o padre, a testemunha e o anunciador da morte, só a conhece agora no hospital. A prática da medicina não hospitalar já não lhe dá a experiência da morte. Desde então, o médico mais bem informado poderá, como se acredita, preparar melhor seus doentes, e ficará menos tentado a se refugiar no silêncio.

A questão essencial é a dignidade da morte. Essa dignidade exige, em primeiro lugar, que a morte seja reconhecida não apenas como um estado real, mas como acontecimento essencial, que não se permite escamotear.

Uma das condições desse reconhecimento é que o moribundo seja informado do seu estado. [...]

Estaremos nós, portanto, às vésperas de uma mudança nova e profunda diante da morte? A regra do silêncio estaria começando a se tornar caduca?

Destarte, até mesmo quem é contra a antecipação da morte, consubstanciada na eutanásia ou então no suicídio assistido, concorda com a questão da necessidade de preservação da integridade psicofísica e, portanto, da integridade corporal do paciente terminal, na medida em que é aceito, pela absoluta maioria das pessoas, o tratamento unicamente paliativo, ao fim da vida, caso em que se pode denotar a opção pela ortotanásia.

Aliás, a autodeterminação corporal, assim como é para a eutanásia e para o suicídio assistido $^{3}$, em relação à possibilidade de embasar a possível efetivação de um "direito ao aborto", nada tem de pacífica. Muito pelo contrário, revela o sempre contundente choque entre aqueles que defendem a mulher e seu direito ao próprio corpo no que toca à interrupção de uma gestação não desejada, e aqueles que rechaçam tal ideal, embasados, sobretudo, no "direito à vida" do feto. ${ }^{4}$

É verdade que, os defensores de um possível direito à vida em relação ao feto, posicionamse de maneira bastante clara e incisiva no sentido de não haver a possibilidade do acolhimento do direito à autodeterminação corporal da mulher em realizar um aborto, por este direito, em tese, colidir com um direito também fundamental (vida), de titularidade de outrem (o feto), e que portanto, não deveria ser acolhido, de modo que este último, até mesmo, ser-lhe-ia prevalecente.

Não se pode deixar de lado, todavia, o também claro e plausível ideal daqueles, ou, em sua maioria, daquelas, que defendem o direito de autodeterminação corporal, inclusive para o fim de realizar um aborto, com base na convicção da existência de um direito ao próprio corpo, e embasando-se na ideia de que tal direito lhes confere subsídios para tanto.

Sobre o assunto, reitera Garcia (2010) a importância de se ponderar sobre a autonomia da mulher, assim como de todo o indivíduo. Ainda, a importância de se perceber as mulheres como seres humanos dotados de qualidades e defeitos, e titulares de direitos, esquecendo-se o ideal por vezes machista de que as mulheres devem viver em um mundo colorido e perfumado, alheias aos acontecimentos mais controversos.

Torna-se necessário, assim, averiguar a questão do abortamento em um contexto mais amplo, que abarca, além do aspecto biológico, o aspecto físico, moral, e emocional, e quanto a isso se aquiesce o demonstrado em Freitas (2010). De certo, todos os assuntos que, para além do cunho

\footnotetext{
${ }^{3}$ Aqui, especifica-se a eutanásia e o suicídio assistido quando se fala em morte digna porque, a ortotanásia já não guarda grandes controvérsias em relação à possibilidade de realização, embora não seja de todo pacífico o entendimento. O procedimento já é, inclusive, considerado ético pelo Conselho Federal de Medicina, por meio da realização das diretivas antecipadas de vontade, consoante se depreende da Resolução 1995/2012, do Conselho Federal de Medicina.

${ }^{4}$ Embora se pense ser imprescindível a menção ao aborto e a um possível direito ao aborto, não se busca aqui fazer uma verificação detalhada acerca da questão das teorias explicativas do início da vida, questionando ser o feto uma vida humana, ou não, detentor, por conseguinte, do direito à vida. Prima-se, isso sim, por explicitar a autodeterminação corporal e demonstrar que, apesar de controversa, ela é diuturnamente levantada, especialmente por quem defende o direito ao aborto.
} 
jurídico, são questões de ordem social, precisam ser ponderados levando-se em consideração todas as variáveis de temas de tamanha envergadura, e é justamente aí que, por via de consequência, entra em pauta o direito à autodeterminação corporal.

Outrossim, sobre o aborto, ressalta Cohen (2012, p. 196):

Isso não é assim porque a mulher seja idêntica a seu útero ou porque o possui, ou porque seja ou possua seu feto, mas porque a experiência da gravidez constitui uma mudança fundamental em sua personificação, nos planos físico, emocional e simbólico e, portanto, em sua identidade e sentimento de individualidade.

Assim, a gravidez é uma experiência extremamente peculiar e porque não dizer, difícil para todas (ou quase todas) as mulheres. As mudanças corporais, e, principalmente, a mudança na identidade psicológica da mulher são muito significativas, e isso em se tratando de mulheres que desejaram aquela gravidez e que se utilizaram de sua autodeterminação corporal para planejar, ou, no mínimo, aceitar aquela gestação.

Essa mudança na identidade, se indesejada, é, para aqueles que defendem o direito de realizar um aborto, acontecimento que enseja o ferimento a direitos primordiais da mulher. Neste momento é que surge a defesa pelo direito de autodeterminação corporal da mulher, para que ela, como pessoa autônoma que é, amparada pelo seu direito ao próprio corpo, decida se quer, ou não, levar adiante tal gestação (indesejada).

Assim sendo, denota-se que todos os assuntos que permeiam as situações emanadas da autonomia decisória e do consequente direito de autodeterminação corporal não são nem um pouco fáceis de serem debatidos, tampouco é fácil a defesa de qualquer dos pontos de vista relacionados a eles. Entretanto, é primordial seja promovida a discussão acerca de tais assuntos, para que, quiçá, um dia, eles possam ser vistos sem capas ou escudos de preconcepções, buscando-se unicamente a proteção do ser humano, da pessoa, em sua dignidade pessoal.

\section{CONCLUSÃO}

O ser humano, em regra, busca a autonomia. Assim, busca ser, e poder ser, de fato, autônomo, para reger o deslinde de sua vida. Sendo dessa forma, a autonomia decisória, explicitada no decorrer do artigo enquanto emanada de um direito à privacidade, precisa ser acatada, nos parâmetros da ciência jurídica, ainda mais porque, é essencial em decisões situadas na zona de intimidade dos indivíduos e que, certamente, geram controvérsias, pela complexidade dos assuntos tratados. De fato, constatou-se que, falar-se em autonomia não é uma tarefa fácil, e, tampouco se trata o termo de um conceito unívoco. O que se pode denotar, a despeito disso, é a importância ímpar que a autonomia possui (e o consequente direito de exercê-la), de forma concreta na vida das pessoas, em absoluto se tratando o tema de discussão meramente teórica.

Sendo assim, a partir de tudo o que foi exposto, algumas considerações podem ser tecidas:

De primeiro plano, a necessidade de pensar-se sobre o direito à privacidade em termos de ordenamento jurídico pátrio, e a partir daí, obviamente, pensar-se sobre a autonomia decisória como subsídio para que o indivíduo possa realizar suas escolhas em um campo próprio de decidibilidade.

Neste sentido, pensa-se que, o direito ao próprio corpo deve ser verdadeiramente reconhecido, não porque se queira dizer que as pessoas possam ou devam fazer com os seus corpos o que queiram, sem nenhum limite, como se ele fosse uma mera mercadoria, mas porque o corpo da pessoa é, no fim das contas, a própria pessoa, e, dessa forma, o sentimento de controle dessa pessoa sobre o corpo mostra-se primordial.

Com isso, reflete-se que a autonomia decisória, anteriormente descrita, confere ao indivíduo poderes para que ele exerça a sua autodeterminação corporal, na medida em que propicia 
os meios necessários para que ele tome posse do seu corpo, para a tomada de decisões de motivação pessoal e particular. Por tais motivos, acredita-se que, a autonomia decisória subsidia, sim, a existência do que se denomina, então, de autodeterminação corporal. O direito ao próprio corpo, já mencionado, precisa ser levado em consideração dentro deste parâmetro, até porque, pode-se dizer que ele se encontra guarnecido pelo poder de proteção oferecido aos direitos da personalidade.

Ademais, considera-se ser imprescindível fomentar o debate acerca dos temas que emanam da análise da autonomia decisória e do consequente direito à autodeterminação corporal, como os descritos no decorrer do texto (principalmente a morte digna e o aborto), além de outros tantos que podem ser citados, como é o caso da opção pela realização de tratamentos médicos (ou não).

Veja-se: ainda que por ventura não se concorde com o ideal de autonomia decisória em relação a esses assuntos, é somente através do seu estudo que serão superados certos mitos e certas barreiras arraigadas no pensamento comum. Aliás, com a análise dos estudos emblemáticos apresentados, pode-se perceber a dimensão do problema exibido, que roga por uma solução que venha ao encontro da defesa da dignidade pessoal, emergindo claramente a noção de eficácia e materialidade a que se propõe o estudo.

Por fim, pode-se considerar que, é inegável a importância da privacidade de decisão, que esteia a pessoa e a empodera para que então ela possa realizar suas escolhas embasadas em seu modo de vida e atuação, e que resguarda-a em sua identidade e consequente dignidade pessoal. Partindo, então, desse pressuposto, acredita-se ser necessário repensar alguns paradigmas impostos, para que se possa, de fato, alcançar a mais profunda possível proteção do ser humano, enquanto pessoa e sujeito de direitos.

\section{REFERÊNCIAS}

AMARAL, Francisco. Direito Civil: introdução. 4. ed. Rio de Janeiro: Renovar, 2002.

ARIÈS, Philippe. O homem diante da morte. Tradução Luiza Ribeiro. 1.ed. São Paulo: Editora Unesp, 2014.

BARROSO, Luís Roberto; MARTEL, Letícia de Campos Velho. A morte como ela é: dignidade e autonomia individual no final da vida. Revista Panóptica: Direito, sociedade e cultura, v. 5, n. 2, p. 69-104, 2010. Disponível em:

<http://www.panoptica.org/seer/index.php/op/article/view/271/293 >. Acesso em: 18 abr. 2017.

BEAUCHAMP, Tom L; CHILDRESS, James F. Princípios de ética biomédica. Tradução Luciana Pudenzi. 3. ed. São Paulo: Loyola, 2013. 574 p. Tradução de: Principles of Biomedical Ethics.

BITTAR, Carlos Alberto. Os direitos da personalidade. Rio de Janeiro: Forense, 1989.

BRASIL. Código Civil. Lei n. 10.406, de 10 de janeiro de 2002. Disponível em: <http://www.planalto.gov.br/ccivil_03/leis/2002/L10406.htm>. Acesso em: 11 nov. 2016.

1988.

Constituição: República Federativa do Brasil de 1988. Brasília, DF: Senado Federal,

CHAVES, Antônio. Direito à vida e ao próprio corpo (intersexualidade, transexualidade, transplantes). 2. ed. rev. e ampl. São Paulo: Revista dos 
Tribunais, 1994. 389 p.

Direitos à vida, ao próprio corpo e às partes do mesmo (transplantes).

Esterilização e operações cirúrgicas para "mudança de sexo". Direito ao cadáver e a partes do mesmo. Revista de Informação Legislativa, Brasília, a. 14, n. 55, p. 125-168, 1977. Disponível em:< http://www2.senado.leg.br/bdsf/item/id/181032 >. Acesso em: 26 jan. 2017.

COHEN, Jean L. Repensando a privacidade: autonomia, identidade e a controvérsia sobre o aborto. Revista Brasileira de Ciência Política, Brasília, n. 7, 2012. Disponível em: $<$ http://www.periodicos.unb.br/index.php/rbcp/article/view/6615/5339 >. Acesso em: 2 set. 2016.

CONSELHO FEDERAL DE MEDICINA. Resolução 1.805, de 9 de novembro de 2006. Diário Oficial da União, Brasília, DF, 28 nov. 2006. Seção I, p. 169. Disponível em: <http://www.portalmedico.org.br/resolucoes/cfm/2006/1805_2006.htm >. Acesso em: 15 jun. 2016.

EISENSTEIN, Zillah. The female body and the law. Berkeley: Universidade Califórnia Press, 1988.

FREITAS, Patrícia Marques. Determinação da filiação e abortamento sob o amparo da Constituição Federal de 1988. In: GARCIA, Maria; GAMBA, Juliane Caravieri; MONTAL, Zélia Cardoso (Coord.). Biodireito Constitucional: questões atuais. Rio de Janeiro: Elsevier, 2010. p. 115-131.

FREITAS, Riva Sobrado de; BAEZ, Narciso Leandro Xavier. Privacidade e o direito de morrer com dignidade. Revista de Ciências Jurídicas Pensar, Fortaleza, v. 19, n. 1, p. 249-269, 2014. Disponível em: <http://periodicos.unifor.br/rpen/article/view/2419/pdf >. Acesso em: 19 ago. 2016.

; PEZZELLA, Maria Cristina Cereser. As dificuldades da constitucionalização do direito ao corpo: liberdade de expressão e discriminação social. Revista Brasileira de Direitos Fundamentais e Justiça, Porto Alegre, ano 7, n. 24, p. 175-195, 2013.

; ZILIO, Daniela. A autonomia decisória na defesa pelo direito de morrer com dignidade. Conpedi Law Review, Uruguai, v.2, n. 4, p. 1-17, 2016a. Disponível em: <http://portaltutor.com/index.php/conpedireview/article/view/357/357 >. Acesso em: 14 abr. 2017.

; ZILIO, Daniela. Os direitos da personalidade na busca pela dignidade de viver e de morrer: o direito à morte (digna) como corolário do direito à vida (digna). Revista de Direitos e Garantias Fundamentais, Vitória, v. 17, n. 1, p. 171-190, 2016b. Disponível em:

<http://sisbib.fdv.br/index.php/direitosegarantias/article/view/733 >. Acesso em: 23 maio 2016.

GARCIA, Maria (Coord.). O aborto e a condição feminina: Nem legalização, nem criminalização. Educação e apoio social: O estatuto da mulher. In: ; GAMBA, Juliane Caravieri; MONTAL, Zélia Cardoso (Coord.). Biodireito Constitucional: questões atuais. Rio de Janeiro: Elsevier, 2010. p. 415-430. 
HABERMAS, Jürgen. O Futuro da Natureza Humana: A caminho de uma eugenia liberal? Tradução Karina Jannini. 2. ed. São Paulo: Martins Fontes, 2010. 159 p. Tradução de: Die Zukunft Der Menschlichen Natur: Auf Dem Weg Zu Einer Liberalen Eugenik?

HONNETH, Axel. Integrity and disrespect: principles of a conception of morality based on the theory of recognition. Political Theory, [S.1.], v. 20, n. 2, p. 187201,1992 .

PESSINI, Léo. Bioética: um grito por dignidade de viver. 4. ed. São Paulo: Paulinas, 2009. 254 p.

STEINMETZ, Wilson. A vinculação dos particulares a direitos fundamentais. São Paulo: Malheiros Editores, 2004. 327 p.

WARREN, Samuel D., BRANDEIS, Louis D. The right to privacy. Harvard Law Review, Boston, vol. IV, n. 5, p. 193-220, 1890. Disponível em: $<$ http://heinonline.org/HOL/Page?handle=hein.journals/hlr4\&div=31\&start_page=193\&colle ction=journals\&set_as_cursor=0\&men_tab=srchresults $>$. Acesso em: 24 jul. 2019.

WOLFF, Kurt (org.). The sociology of Georg Simmel. New York/London: The Free Press, 1950. 